\title{
APLICAÇÃO IN-SITU DE UMA NOVA FONTE DE ENZIMAS OXIDÁSICAS FÚNGICAS NA GERAÇÃO DE ENERGIA EM BIO- CÁTODOS PARA CÉLULA A COMBUSTÍVEL
}

\author{
Kyriale Vasconcelos Morant ${ }^{1,2}$; Paulo Henrique da Silva ${ }^{1,2}$; Galba M. de Campos-Takaki ${ }^{2}$ \\ Camilo E. La Rotta H. ${ }^{2}$ \\ ${ }^{1}$ Departamento de Engenharia Química, Universidade Católica de Pernambuco \\ ${ }^{2}$ Núcleo de Pesquisas em Ciências Ambientaise Biotecnologia, Universidade Católica de \\ Pernambuco, \\ E-mail para contato: kyrialem@yahoo.com.br
}

\begin{abstract}
RESUMO - Em biocélulas a Combustível (BCC), o uso de enzimas oxidásicas no lugar de catalisadores metálicos para a redução catódica de oxigênio, pode diminuir os seus custos de fabricação e operação. No entanto, o uso de biocatalisadores está restrito pelos custos de isolamento e estabilização. Assim, a produção e aplicação in-situ vêm sendo estudadas. Neste trabalho, uma nova cepa de Rhyzopus microsporus var. chinensis (SIS-31), com atividade oxidásica, isolado de solos da Caatinga, foi submetido a fermentações de $240 \mathrm{~h}$ e a cultivo in-situ no cátodo da BCC por $120 \mathrm{~h}$ em meio de cultura otimizado. Foram medidos parâmetros microbiológicos de consumo de substrato, atividade enzimática e crescimento microbiano, assim como parâmetros eletroquímicos de eficiência culômbica através de cronoamperametria, comportamento redox por ciclovoltametria e densidade de potencia máxima por polarização. Os resultados obtidos para a nova fonte fúngica com atividade oxidásica foram comparados com a Lacase comercial de Tramentes versicolor usada como padrão. Os valores máximos atingidos de atividade oxidásica, densidade de corrente (Id) e eficiência coulômbica (EC) foram de 2700 UI.mL $L^{-1}, 125,75 \mu$ A.cm ${ }^{-2}$ e de $56,5 \%$, respetivamente. A densidade de potencia máxima $\left(\operatorname{Pd}_{\max }\right)$ achada para o sistema avaliado foi de $197,77 \mathrm{~mW} \mathrm{~m}^{-3}$. Valores de EC > 20\%, para BCC, já são considerados ótimos. Baseado nisto, o sistema mostrou-se extremamente eficiente.
\end{abstract}

\section{INTRODUÇÃO}

As Células a Combustível (CC) começaram a ser formuladas como uma alternativa renovável e limpa na produção de energia, frente aos combustíveis fósseis. Esta procura vem sendo cada dia mais intensa, tendo em vista que a cada dia consume-se mais energia. No entanto, o alto custo dos catalisadores metálicos, tais como platina $(\mathrm{Pt})$, ósmio $(\mathrm{Os})$, ródio $(\mathrm{Rh})$, etc, é considerado um dos limitantes para a produção em larga escala das CC e algumas Biocélulas a Combustível (BCC) (LUO et al., 2010). As BCC são consideradas uma alternativa promissora para a geração de energia limpa, obedecendo também requisitos de sustentabilidade. Em geral, a biocélula a combustível é um dispositivo que converte energia química da matéria orgânica em energia elétrica, utilizando a respiração celular de alguns micro-organismos, que podem crescer a 


\section{9 a 22 de outubro de 2014 \\ Florianópolis/SC}

partir de substratos renováveis e biodegradáveis. Nela pode acontecer simultaneamente tanto a produção de bioenergia como o tratamento concomitante de resíduos (DANTAS et al., 2013; LA ROTTA et al., 2014; KARATAY et al., 2011; RACHINSKI et al., 2010, ). No entanto, até agora a produção de energia obtida das BCC não é satisfatória. Além disso, o desempenho na geração de energia pode ser afetado por uma série de fatores, tais como a atividade celular, membranas de troca de iônica, materiais eletródicos e a resistência inerente do sistema devida aos problemas de transferência de carga e massa. Cátodos abióticos que usam o oxigênio como receptor de elétrons, têm sido comumente adotados nas BCC. Quanto mais metal pesado tiver no eletrodo, maior a sua eficiência, porém também aumenta o custo, além do material ser sensível ao envenenamento (GUPTA et. al. 2004). Atualmente, as células enzimáticas não são muito utilizadas devido ao seu alto preço, pois é levado em conta a purificação e produção, contrapostas com o curto tempo de vida útil. Assim sendo, as BCC inoculadas com fungos filamentosos produtores de metabólitos eletroativos podem oferecer uma solução em potencial (LOGAN e REGAN, 2006). As enzimas empregadas em biocátodos correspondem às oxido-redutases que em geral possuem no sítio ativo um ou mais átomos de cobre ou ferro, um exemplo destas são a lacase, tirosinase e bilirrubina oxidase. Estas enzimas são encontradas em alguns fungos filamentosos, tais como Agaricus bisporus, Myrothecium verrucaria, Coriolus hirsutus, Trametes versicolor, Coriolopsis gallica, Pleurotus ostreatus, e Phanerochaete crysosporium; em plantas como Rhus vernicifera e bacterias como Streptomyces coelicolor (MANO et al., 2002; BARTON et al., 2002; GUPTA et al. 2004; SHLEEV et al., 2006).

O projeto da Rede Norte Nordeste de Fungos Filamentosos (RENNORFUN) visa descrever a biodiversidade de fungos filamentosos de solos da Caatinga e da Amazônia e dos metabolitos por estes produzidos, assim como a aplicabilidade na produção de insumos de interesse industrial e reaproveitamento de resíduos. Por outro lado, a aplicação de alguns destes metabolitos com propriedades eletrogênicas em biocélulas a combustível vêm sendo estudadas no grupo de bioeletroquímica do NPCIAMB da Universidade Católica de Pernambuco. O objetivo deste trabalho foi o de caracterizar desde o ponto de vista bioeletroquímico a capacidade de geração de energia em biocátodos ao ar de uma BCC, o crescimento in-situ de um fungo filamentoso com comprovada atividade oxidásica.

\section{MATERIAIS E MÉTODOS}

\subsection{Micro-organismos e condições de cultura}

O micro-organismo utilizado foi o Rhyzopus microsporus var. chinensis (SIS-31), isolado do solo da Caatinga pelo grupo de pesquisa da RENNORFUN e mantido no banco de cepas do NPCIAMB da UNICAP. O microrganismo foi cultivado no meio descrito incialmente por Buddolla Viswanath et al. (2008) e modificado por Morant et al. (2013a) para estimular a produção de cuproproteinas com atividade oxidásica. Este meio foi composto de: peptona 3,0 g, glucose $10,0 \mathrm{~g}, \mathrm{KH}_{2} \mathrm{PO}_{4}$ 0,6 g, $\mathrm{ZnSO}_{4}$ 0,001 g, $\mathrm{K}_{2} \mathrm{HPO}_{4}$ 0,4 g, $\mathrm{FeSO}_{4}$ 0,0005 g, $\mathrm{MnSO}_{4}$ 0,05 g, $\mathrm{MgSO}_{4}$ 0,5 g, $\mathrm{CuSO}_{4}$ 0,0005 g, água destilada $1000 \mathrm{~mL}$. Para o cultivo em placa, adiciona-se 20,0 g de ágar. O microrganismo foi inoculado em placas de Petri contendo o meio sólido anteriormente descrito. Incubado por $48 \mathrm{~h}$ a $28^{\circ}$ C. A partir dos entornos da colônia (a parte mais jovem e uniforme), foram retirados dois discos de 

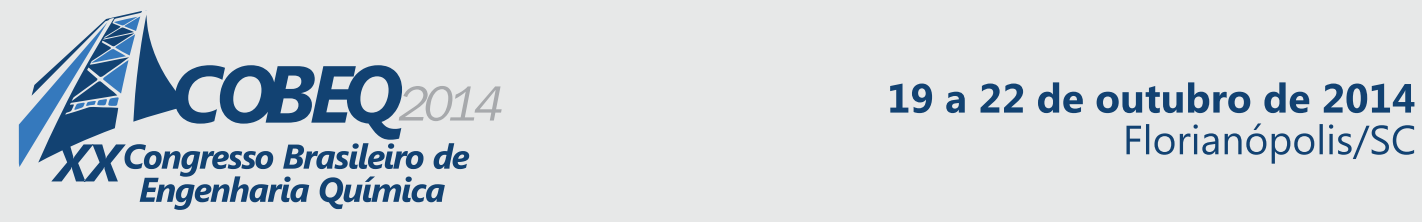

$0,8 \mathrm{~cm}$ de diâmetro os quais foram cortados em quatro partes e inoculados em um tubo de ensaio contendo $10 \mathrm{~mL}$ do meio de cultura líquido, a serem usados como pré-inóculo. Após $48 \mathrm{~h}$ de incubação a $28^{\circ} \mathrm{C}$ e agitação $150 \mathrm{rpm}$, os pré-inóculos foram adicionado nos respectivos Erlenmeyers e estes foram mantidos sob as mesmas condições de temperatura e agitação de 120 a $240 \mathrm{~h}$ dependendo da finalidade.

\subsection{Avaliação de parâmetros biológicos:}

Foram retiradas amostras a cada $24 \mathrm{~h}$, durante todo o tempo da fermentação de $240 \mathrm{~h}$. As amostras foram centrifugadas a $4500 \mathrm{rpm}$, a fim de separar o sobrenadante, e em seguida congeladas. A dosagem de glicose foi feita por kit enzimático da marca BIOCLIN®. A atividade enzimática foi dosada através da oxidação do pirogalol (solução aquosa de $10 \mathrm{mmol} \mathrm{L}^{-1}$ ) para a purpurogalina. A reação foi lida a $420 \mathrm{~nm}\left(\mathrm{E}_{420 \mathrm{~nm}}=26,6 \mathrm{mmol}^{-1} \mathrm{~L} \mathrm{~cm}^{-1}\right)$ após três minutos (MORANT et al. 2013a; TRIANA et al. 2005). A atividade oxidásica $\left(\mathrm{UI} \mathrm{mL}^{-1}\right)$ foi definida como a quantidade $\mu$ moles por $\mathrm{mL}$ por minuto de purpurogalina formadas a $25^{\circ} \mathrm{C}$ e $\mathrm{pH} 5,0$. Já para o crescimento microbiano, ao final de cada fermentação o conteúdo foi filtrado e centrifugado a $4500 \mathrm{rpm}$. O micélio foi mantido a uma temperatura de $50^{\circ} \mathrm{C}$ por $48 \mathrm{~h}$ ou até peso constante.

\subsection{Análise bioeletroquímica.}

Crornoamperometria: Os pré-inóculos foram vertidos em dois Erlenmayers de $500 \mathrm{~mL}$ com volume de $200 \mathrm{~mL}$ de meio de cultura, $100 \mathrm{~mL}$ de um Erlenmayer foram colocados no compartimento catódico da BCC (Figura 1), esta também em agitação magnética. A duplicata foi guardada como controle e o que restou do Erlenmayer vertido na BCC foi utilizado para possíveis imprevistos no experimento. Foi utilizado um multímetro Digital Fluke 8800 com sistema de aquisição de dados Flukeview®, acoplado a uma BCC de dois compartimentos feitos de acrílico com resistência externa variável de 0 a $1 \mathrm{~K} \Omega$. O compartimento catódico recebeu aeração através de um eletrodo ar permeável, composto por feltro de carbono tratado teflon e carbono Black Vulcan®; o ânodo foi composto de uma placa de grafite explodido submerso no eletrólito de Ferrocianeto de potássio $\left(20 \mathrm{mmol} \mathrm{L}^{-1}\right)$. Ambos dos eletrodos possuíram uma área superficial de 19,6 $\mathrm{cm}^{2}$. Para o transporte de cátions, foi usada uma ponte salina de ágar saturado com cloreto de potássio $(\mathrm{KCl})$ (Figura 1A). Já para a eficiência da remoção de elétrons a partir de cada molécula de substrato consumida pelo fungo, foi utilizado o parâmetro de Eficiência Coulômbica $(\mathrm{Ce})$ obtido através da integração das curvas resultantes da cronoamperometria (Equação 1). Onde " $M$ " é a molaridade do substrato, " $A$ " representa a área do eletrodo, " $F$ " a constante de Faraday, " $z$ " o número de elétrons transferidos, " $V$ " o volume da célula e " $\Delta S$ ” a variação na concentração de substrato.

$$
C e=M * \frac{\int_{0}^{t f} i d * d t * A}{F * Z * V * \Delta S}
$$

Ciclovoltametria: Esta técnica nos permitiu conhecer o comportamento redox dos extratos enzimáticos crus, através da observação do número e a reversibilidade das oxidações e reduções que ocorrem durante cada ciclo (FERNÁNDEZ-SÁNCHEZ et al., 2002; MORANT et al. 2013a; RACHINSKI et al., 2010.). As medidas foram feitas numa célula eletroquímica de $25 \mathrm{~mL}$ (Figura 
1B), de acordo com condições previamente estabelecidas (MORANT et al., 2013a,b; SILVA et al., 2014). Foram utilizadas velocidades de varredura de $0,05 \mathrm{~V} \mathrm{~s}^{-1}$, com faixas de potencial de $0,5 \mathrm{~V}$ a 0,0 V. e depois de $0,8 \mathrm{~V}$ a $-0,5 \mathrm{~V}$. O eletrodo de trabalho for de carbono vítreo de $0,5 \mathrm{~cm}$ de diâmetro, o contra eletrodo de fio de platina de $5 \mathrm{~cm}$ e o eletrodo de referência ( $\mathrm{Ag} \mid \mathrm{AgCl}$ em $\mathrm{KCl}$ saturado).

Polarização: Curvas de polarização de (E vs. Id) foram obtidas numa célula bicompartimentada de $100 \mathrm{~mL}$ com cátodo ao ar. Foi colocado no compartimento catódico o eletrodo de referência ( $\mathrm{Ag} \mid \mathrm{AgCl}$ em $\mathrm{KCl}$ saturado) de acordo com a Figura 1C. As curvas de polarização foram obtidas na faixa de potencial de $0,85 \mathrm{~V}$ a $-0.5 \mathrm{~V}$ utilizando com $\mathrm{OCP}=0.85 \mathrm{~V}$ vs. $\mathrm{Ag} \mid \mathrm{AgCl}$. $\mathrm{O}$ valor de densidade de potencia máxima foi determinada graficamente a partir da determinação dos valores de Pd de acordo com a Equação 2, e das curvas de (Pd vs Id) .

$$
P d_{\text {máx }}=E * i
$$
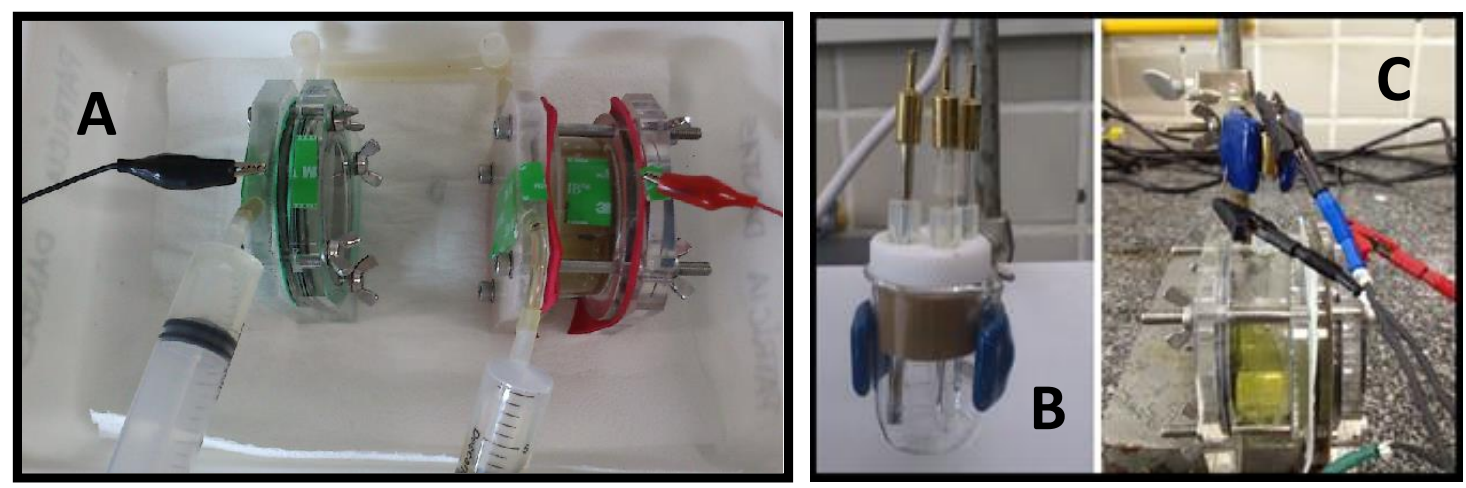

Figura 1 - (A) BCC, à direita, compartimento catódico com crescimento in-situ, e à esquerda o ânodo com ferrocianeto de potássio $20 \mathrm{mmol} \mathrm{L}^{-1}$. (B) Célula unitária eletroquímica utilizada na cilovoltametria.(C) Célula bicompartimentada utilizada durante a polarização.

\section{RESULTADOS E DISCUSSÃO}

\subsection{Fermentações}

Ao fim das $240 \mathrm{~h}$ de fermentação, a glicose foi consumida quase por completo, restando apenas $0,12 \%$ da concentração inicial. A maior atividade enzimática foi observada às $192 \mathrm{~h}, \mathrm{com}$ $6275,30 \mathrm{UI}$, e o peso seco médio final de $1,2 \mathrm{~g}$.

\subsection{Crescimento in-situ no biocátodo}

Durante todas as $120 \mathrm{~h}$, a BCC foi acompanhada para o SIS 31 e o padrão de lacasse. A Tabela 1 mostra todos os dados obtidos na célula. O SIS-31 apresentou uma alta eficiência coulômbica $(\mathrm{Ce})$, de 56,5\% de acordo com os perfis observados na Figura 2. 
Tabela 1 - Dados obtidos na BCC, com o SIS-31 e controle de lacase

\begin{tabular}{|c|c|c|c|c|c|c|}
\hline Oxidase - origem & 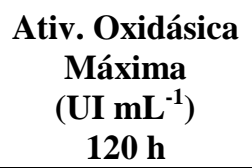 & $\begin{array}{c}\mathbf{I d}_{\text {máx }} \\
\left(\mu \mathrm{A} \mathbf{c m}^{-2}\right)\end{array}$ & $\begin{array}{l}\text { Tempo da } \\
\text { Id }_{\text {máx }} \\
\text { (h) }\end{array}$ & $\begin{array}{c}\text { Glicose } \\
\left(\mathrm{g} \mathrm{L}^{-1}\right) \\
120 \mathrm{~h}\end{array}$ & $\begin{array}{l}* \mathrm{Ce} \\
(\%)\end{array}$ & $\underset{\left(\mathbf{m W} \cdot \mathbf{m}^{-2}\right)}{\mathbf{P d}_{\text {máx }}}$ \\
\hline $\begin{array}{l}\text { R. microsporus var. } \\
\text { chinensis (SIS-31) }\end{array}$ & 2700 & 125.75 & 23 & 0.003 & 56.5 & 224,08 \\
\hline $\begin{array}{l}\text { Controle - Lacase } T \text {. } \\
\text { versicolor }\end{array}$ & $900 *$ & 11.47 & 1 & - & - & 43,40 \\
\hline
\end{tabular}

Valores de Ce de $20 \%$ já são considerados ótimos, mostrando assim a alta eficiência do sistema. As ciclovoltametrias (Figura 3) mostraram comportamentos típicos de um meio contendo uma enzima oxidase a julgar pelos picos existentes. Ressalvam-se os dois picos de oxidação nas curvas de cilovoltametria com e sem a presença de pirogalol (adicionado como substrato da enzima), este apenas acentuando-os (Figura 4). Das curvas de polarização podemos calcular a potência máxima que o sistema atingiu no ponto final foi de $197,77 \mathrm{~mW} . \mathrm{m}^{-2}$ (Figura 5). Experimentos anteriores de mostraram perfis parecidos de ciclovoltametrias, o SIS-31 apresentou dois picos de oxidação, ao passo em que os outros apresentaram apenas um, possivelmente indicando a presença de uma enzima oxidase diferente. O SIS-31 apresentou uma maior densidade de corrente e EC frente aos outros fungos da Caatinga até agora analisados pelos autores supracitados.

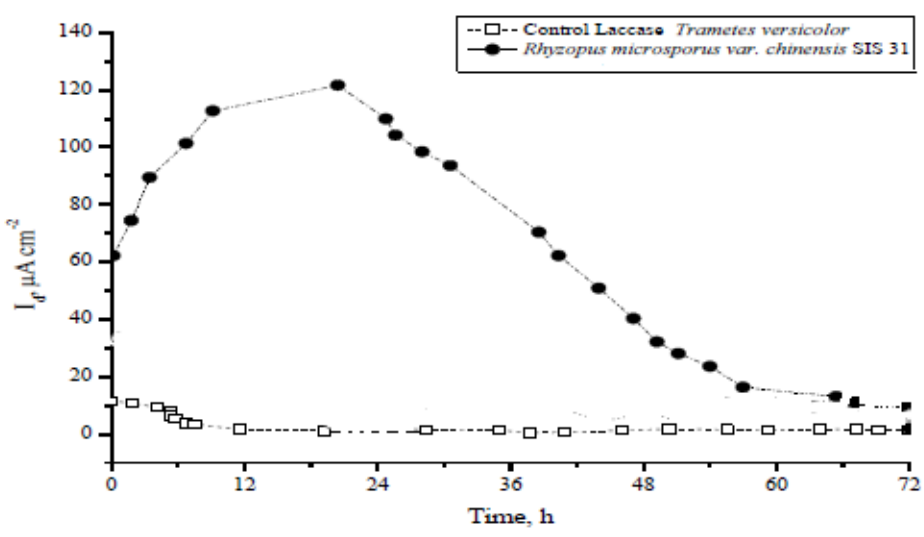

Figura 2 - Gráfico da cronoamperometria até as primeiras 72 h, comparando o desempenho do SIS-31 com o controle de lacase na produção de energia in-situ. 


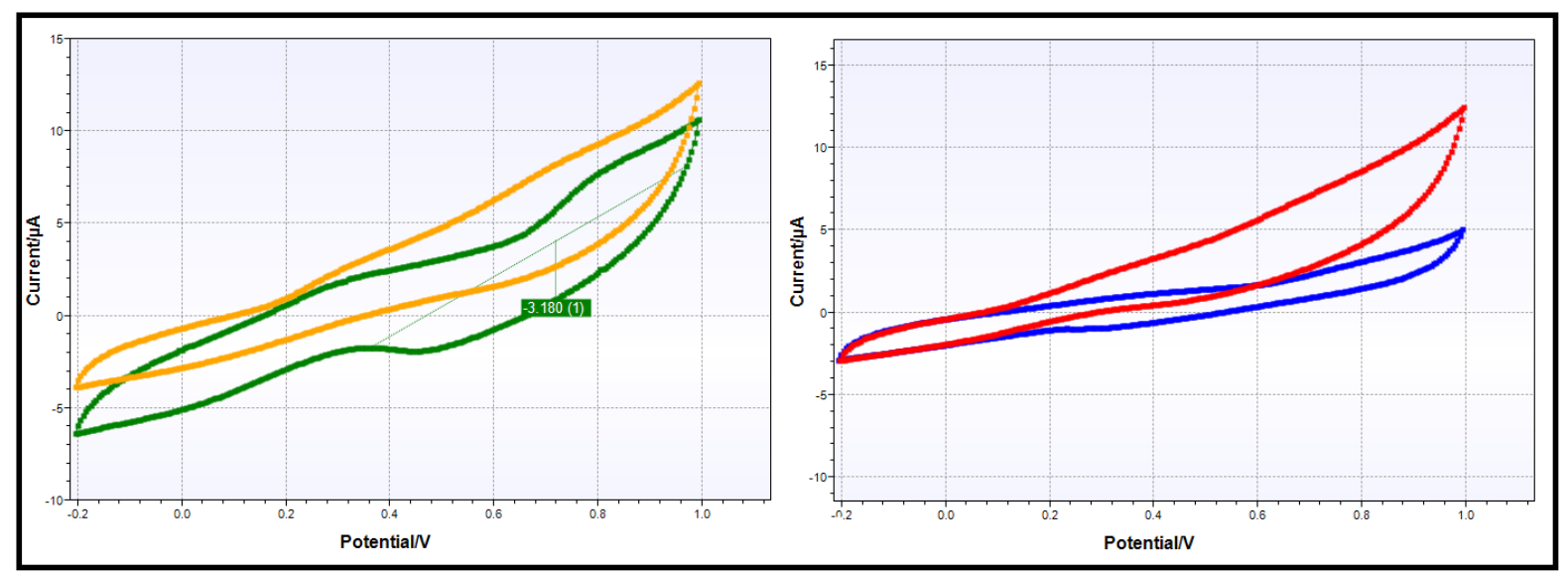

Figura 3 - Ciclovoltametria do SIS-31. À esquerda tem-se o gráfico de controle (branco) com o meio de cultura, em amarelo com adição de pirogalol, e em verde o meio de cultura puro. Ao lado direito, o meio do SIS-31 filtrado, contendo a enzima, com a curva vermelha mostrando a adição de pirogalol e azul apenas o meio com enzima.

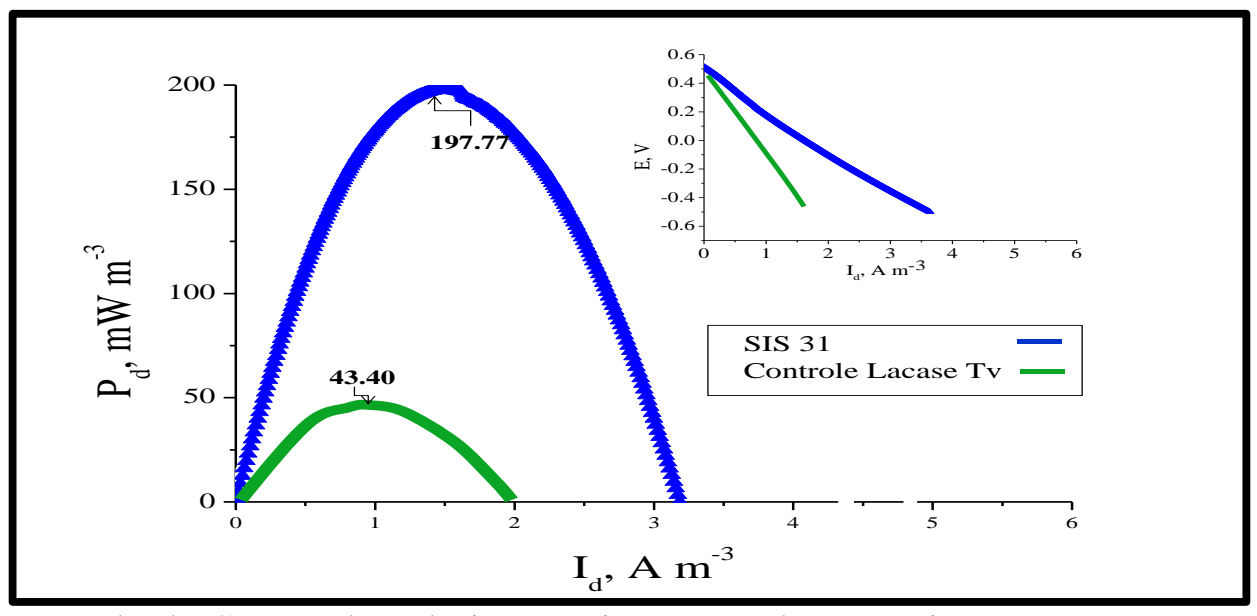

Figura 4 - Exemplo de Curvas de polarização (inserto) e de potencia para o extrato enzimático de SIS 31 contendo $2700 \mathrm{UI} \mathrm{mL} \mathrm{m}^{-1}$ avaliadas na faixa de potencial de -0.5 a $0 \mathrm{~V}$.

\section{Conclusões}

O Rhyzopus microsporus var. chinensis (SIS-31) corresponde a uma espécie ainda não reportada como fonte de enzimas oxidásicas. Omo foi demostrado, este microrganismo pode ser usado durante a redução de oxigênio em biocátodos de Biocélulas a Combustível, mostrando ser bastante eficiente. Atualmente o nosso trabalho pretende a caracterização de outras espécies fúngicas que possuam iguais ou melhores características bioquímicas e bioeletroquímicas como as observadas para o microrganismo avaliado neste trabalho. Visamos ainda estudos de otimização das condições de cultura e eletroquímicas para aumentar ainda mais os níveis de produção dos biocatalisadores e de eficiência culômbica durante a biotransformação dos substratos escolhidos. 


\section{9 a 22 de outubro de 2014 \\ Florianópolis/SC}

\section{AGRADECIMENTOS}

Os autores agradecem o apoio financeiro dado pelos programas de Desenvolvimento Científico Regional através do projeto DCR No.0008-1.06/11 e do Programa de Bolsas de Iniciação Científica do Conselho Nacional de Pesquisa - CNPq e da Fundação para o Amparo à Pesquisa e Tecnologia do Estado de Pernambuco - FACEPE

\section{BIBLIOGRAFIA}

BARTON, S.C.; PICKARD, M.; VAZQUEZ-DUHALT, R.; HELLER, A. Electroreduction of O2 to water at $0.6 \mathrm{~V}$ (SHE) at $\mathrm{pH} 7$ on the 'wired' Pleurotus ostreatus laccase cathode. Biosensors and Bioelectronics v. 17, p.1071-1074, 2002.

DA SILVA, P. H.; MORANT, K. V.; CAMPOS-TAKAKI, G. M.; LA ROTTA, C. E. Production of electrogenic pigments from new fungal sources applied as electron shuttles in biofuel cells. Industrial, medical and environmental applications of microorganisms: current status and trend. SN. ed. Madrid: Wageningen Academic Publishers, 2014.

DANTAS, P. V.; PERES S.; TAKAKI, G. M. C.; LA ROTTA, C.E.H. . Utilization of Raw Glycerol for Pyocyanin Production from Pseudomonas Aeruginosa in Half-Microbial Fuel Cells: Evaluation of Two Electrochemical Approaches. Journal of the Electrochemical Society, v. 160, p. G1-G7, 2013.

FARNETH, W. E.; D'AMORE, M. B. Encapsulated laccase electrodes for fuel cell cathodes. Journal of Electroanalytical Chemistry v. 581 p. 197-205, 2005.

FARNETH, W. E.; DINER, B. A.; GIERKE, T. D.; D'AMORE, M. B. Current densities from electrocatalytic oxygen reduction in laccase/ABTS solutions. Journal of Electroanalytical Chemistry. v. 581 p. 190-196, 2005.

FERNÁNDEZ-SÁNCHEZ, C.; TZANOV, T.; GÜBITZ, G. M.; CAVACO-PAULO, A. Voltammetric monitoring of laccase-catalysed mediated reactions. Bioelectrochemistry v.58, p. 149- 156, 2002.

GHADIRI, M.; KARIMINIA, H.R.; AZAD, R. R. Spectrophotometric determination of sulfide based on peroxidase inhibition by detection of purpurogallin formation. Ecotoxicology and Environmental Safety v.91 p.117-121, 2013.

GUPTA, G.; RAJENDRAN, V.; ATANASSOV, P.; Bioelectrocatalysis of oxygen reduction reaction by laccase on gold electrodes. Electroanalysis. v. 6, p. 1182-1185, 2004.

KARATAY, S.E.; DONMEZ, G. Microbial oil production from thermophile cyanobacteria for biodiesel production. Appl Energy. V. 88, p. 3632-5, 2011.

LA ROTTA C.E.H ; LEITE, A. L. ; PERES R.S. ; DANTAS, P. V. ; TAKAKI, G. M. C. . Hybrid 


\section{9 a 22 de outubro de 2014 \\ Florianópolis/SC}

Microbial-Photosynthetic Biofuel Cells for Simultaneous Bacterial Glycerol Biotransformation and Algal Carbon Dioxide Capture. J. Braz. Chem. Soc., Vol. 25, No. 3, p. 560-571, 2014

LOGAN, B. E.; REGAN, J. M.; Microbial fuel cell: challenges and technology Environ. Sci. Technology. v. 40, p. 5172-5180, 2006.

LUO, H.; JIN, S.; FALLGREN, H. P.; PARK, H. J.; JOHNSON, P. A. A novel laccase-catalyzed cathode for microbial fuel cells. Chemical Engineering Journal v. 165 p. 524-528, 2010.

MANO, N.; KIM, H. H.; HELLER, A. On the relationship between the characteristics of bilirubin oxidases and $\mathrm{O} 2$ cathodes based on their "wiring", J. Phys. Chem. B. v. 106, p. 8842-8848, 2002.

MORANT, K. V., CAMPOS-TAKAKI, G. M.; LA ROTTA, C. E. Estudo da produção de enzimas com propriedades eletroquímicas por fungos filamentosos isolados do solo da Caatinga a serem usadas em Células a Combustível Microbianas. Anais da XV Jornada de Iniciação Científica da Universidade Católica de Pernambuco. Recife, Brasil. No. 15 p.36, 2013a

MORANT, K. V., DA SILVA, P. H.; CAMPOS-TAKAKI, G. M.; LA ROTTA, C. E. Screening for new fungi with oxidasic activity applied in-situ as biocatalysts for biofuel cells. Anais da V International Conference on Environmental, Industrial and Applied Microbiology BioMicroWorld2013. Madrid, Espanha. p. 704, 2013b

RACHINSKI, S.; CARUBELli, A.; MANGONI, A.P.; MANGRICH, A.S. Pilhas de Combustíveis Microbianas Utilizadas na Produção de Eletricidade a Partir de Rejeitos Orgânicos: Uma Perspectiva de Futuro Quimica Nova, Vol. 33, No. 8, p. 1773-1778, 2010.

SHLEEV, S.; PITA, M.; YAROPOLOV, A.I.; RUZGAS, T.; GORTON, L. Direct heterogeneous electron transfer reactions of Trametes hirsuta laccase at bare and thiol-modified gold electrodes. Electroanalysis. v. 18, p. 1901-1908, 2006.

TRIANA, G.; BÁRBARA E.; PEÑA PINO, ROBERTO DE LA; RODRÍGUEZ SOSA, VÍCTOR; SALDAÑA BERNABEU, ALBERTO; GARCÍA PIÑEIRO, JOSÉ C. Efecto del Vimang Sobre la Actividad Serica de Enzimas Antioxidantes en la Periodontitis Experimental. Instituto Superior de Ciencias Médicas de la Habana. Revista Habanera de Ciencias Médicas. v. 4, n. 3, 2005.

VISWANATH, B.; CHANDRA, M. S.; PALLAVI, H.; REDDY B. R. Screening and assessment of laccase producing fungi isolated from different environmental samples. African Journal of Biotechnology ISSN 1684-5315. v. 7, n. 8, p. 1129-1133, 2008.

XICAN LI. Improved Pyrogallol Autoxidation Method: A Reliable and Cheap SuperoxideScavenging Assay Suitable for All Antioxidants. Journal of Agricultural and Food Chemistry v. 60, p. 6418-6424, 2012. 